\title{
Role of MeCP2, DNA methylation, and HDACs in regulating synapse function
}

\author{
Ege T. Kavalali • Erika D. Nelson • Lisa M. Monteggia
}

Received: 2 December 2010 / Accepted: 14 February 2011 /Published online: 2 March 2011

(C) Springer Science+Business Media, LLC 2011

\begin{abstract}
Over the past several years there has been intense effort to delineate the role of epigenetic factors, including methyl-CpG-binding protein 2, histone deacetylases, and DNA methyltransferases, in synaptic function. Studies from our group as well as others have shown that these key epigenetic mechanisms are critical regulators of synapse formation, maturation, as well as function. Although most studies have identified selective deficits in excitatory neurotransmission, the latest work has also uncovered deficits in inhibitory neurotransmission as well. Despite the rapid pace of advances, the exact synaptic mechanisms and gene targets that mediate these effects on neurotransmission remain unclear. Nevertheless, these findings not only open new avenues for understanding neuronal circuit abnormalities associated with neurodevelopmental disorders but also elucidate potential targets for addressing the pathophysiology of several intractable neuropsychiatric disorders.
\end{abstract}

Keywords HDAC · DNA methylation $\cdot \mathrm{MeCP} 2$.

Neurotransmission $\cdot$ Synaptic plasticity

\section{From the nucleus to the synapse: transcriptional regulation of synaptic function}

The last two decades have witnessed significant advances in our understanding of gene regulation in neurons. In

\section{E. T. Kavalali $\cdot$ E. D. Nelson}

Department of Neuroscience, University of Texas Southwestern

Medical Center,

Dallas, TX 75390-9111, USA

L. M. Monteggia $(\triangle)$

Department of Psychiatry, University of Texas Southwestern

Medical Center,

5323 Harry Hines Blvd,

Dallas, TX 75390-9070, USA

e-mail: lisa.monteggia@utsouthwestern.edu particular, synaptic activity has been shown to be a critical regulator of neuronal gene expression. A number of studies have focused on the role of synaptic $N$-methyl-D-aspartic acid (NMDA) receptors as well as dendritic L-type $\mathrm{Ca}^{2+}$ channels and their downstream $\mathrm{Ca}^{2+}$-dependent targets in regulation of neuronal transcription within the nucleus (Deisseroth et al. 2003). These processes have been shown to be essential for long-term neuronal adaptations and maintenance of synaptic plasticity. However, the impact of retrograde nuclear signaling and neuronal gene transcription on synaptic function has only recently begun to be elucidated. In this context, Rett syndrome and methyl-CpGbinding protein 2 (MeCP2)-dependent neuronal gene regulation have provided a Rosetta stone for how alterations in transcription may impact neuronal function and in turn affect behavior. These studies highlight the critical role of epigenetic mechanisms such as histone acetylation and DNA methylation in the regulation of synaptic function.

\section{Rett syndrome}

Rett syndrome (RTT) is a childhood neurological disorder that is one of the most prevalent causes of mental retardation and autistic behavior in females (Hagberg et al. 1983). Individuals affected with RTT typically experience normal development up to the age of 6-18 months at which time they fail to acquire new skills and enter a period of motor skill regression. With time, the RTT defects become more pronounced and include a wide range of neurological deficits including stereotypical hand movements, mental retardation, autism-like behavior, seizures, disturbances of sleep, problems with gait, and decelerated head growth. Clinical research over the past decade has demonstrated that RTT is an X-linked disorder that in the vast majority of cases $(>96 \%)$ results from heterozygous mutations in the coding region of the $\mathrm{MeCP} 2$ gene (Amir et 
al. 1999; Amir and Zoghbi 2000; Bienvenu et al. 2000; Huppke et al. 2000; Ravn et al. 2005; Wan et al. 1999). These mutations are predicted to result in loss of MeCP2 function (Ballestar et al. 2000; Yusufzai and Wolffe 2000). The MeCP2 gene encodes a DNA-binding protein that binds to methylated cytosines in DNA and then interacts with a multiprotein corepressor complex containing the proteins histone deactylases 1 and 2 (HDAC1 and HDAC2) and $\operatorname{Sin} 3 \mathrm{~A}$. Traditionally, MeCP2 is believed to act as a transcriptional repressor by binding to target gene promoters and silencing their transcription. However, initial microarray analyses from brain tissue of MeCP2 null knockout (KO) mice showed only subtle changes in gene expression and failed to identify genes that are relevant to the pathology of RTT (Tudor et al. 2002). More recent microarray data has confirmed the transcriptional repressor function of $\mathrm{MeCP} 2$ and suggests that it may also function as a transcriptional activator (Chahrour et al. 2008; Lasalle and Yasui 2009), although it is possible that MeCP2dependent transcriptional activation occurs via MeCP2's repression of additional transcriptional repressors.

While MeCP2 is expressed in many tissues, it is interesting that the majority of RTT deficits are pronounced in the central nervous system (CNS). MeCP2 is expressed at high levels in the mammalian brain, in particular, in neurons although low levels of expression have been reported in glia (Ballas et al. 2009). In immature neurons, $\mathrm{MeCP} 2$ expression is low but increases during neuronal maturation and reaches its highest level of expression in postmitotic neurons (Kishi and Macklis 2004; Matarazzo et al. 2004). This developmental profile of MeCP2 expression may suggest that $\mathrm{MeCP} 2$ is involved in neuronal maturation and dendritic arborization (Francke 2006). Interestingly, this high level of MeCP2 expression in postmitotic neurons continues throughout adulthood suggesting that $\mathrm{MeCP} 2$ may also play an important role in mature neurons.

Attempts to model RTT by generating constitutive $\mathrm{MeCP} 2 \mathrm{KO}$ mice have resulted in the recapitulation of some of the neurological symptoms of the disorder, although these mice die early in postnatal development precluding behavioral characterization (Chen et al. 2001; Guy et al. 2001; Tate et al. 1996). Conditional KO mice were generated to circumvent this complication, in which floxed MeCP2 mice were crossed with calcium-calmodulin-dependent protein kinase II (CaMKII)-Cre transgenic mice to selectively delete MeCP2 in brain (Chen et al. 2001). This CaMKII-Cre mouse line expresses Cre recombinase in forebrain regions during early postnatal (P14) development. These conditional MeCP2 $\mathrm{KO}$ mice have many of the behavioral abnormalities that are reminiscent of the symptoms seen in RTT patients, including impaired motor coordination, increased anxiety, and abnormal social interaction with other mice (Gemelli et al. 2006). In a way, it was rather surprising that deletion of $\mathrm{MeCP} 2$ in postmitotic neurons would recapitulate some of the behavioral phenotypes of RTT and suggests that MeCP2 plays an important role in mature neurons past neurodevelopment. What is more, the CaMKII gene is selectively expressed in excitatory neurons and thus, the fact that deletion of MeCP2 specifically in this neuronal subtype mimics some of the disease phenotypes highlights an important role for excitatory neurons in the etiology of the disorder. Various other conditional MeCP2 knockout lines have now been generated and are revealing important temporal and spatial roles for MeCP2 in the brain. RTT-like phenotypes have also been observed in mice lacking expression of MeCP2 in inhibitory GABAergic neurons (Chao et al. 2010), various aminergic neurons (Samaco et al. 2009), and a subset of hypothalamic neurons (Fyffe et al. 2008).

While conditional MeCP2 KOs recapitulate many of the behavioral phenotypes associated with RTT patients, no major neuroanatomical abnormalities or neuronal loss were observed in these mice (Chen et al. 2001). Other RTT mouse models as well as the brains of RTT patients have not reported any major neuronal loss but rather only slight reductions in neuronal size and overall brain volume and subtle changes in neuronal morphology (Kaufmann and Moser 2000; Kishi and Macklis 2004; Shahbazian et al. 2002). One of the most consistent changes in neuronal morphology in animal models of the disorder, and importantly, in postmortem brains of RTT patients, are alterations in dendritic and synaptic spine structure indicative of a malfunction of synaptic development and plasticity (Jugloff et al. 2005; Kaufmann and Moser 2000). This finding is particularly intriguing since individuals affected with RTT experience normal development up to a time period that includes pronounced synaptogenesis and synaptic pruning in cortical regions of the brain, at which time they then start to manifest the behavioral phenotypes associated with the disorder. Recent work has demonstrated that alterations in dendritic structure can result from changes in synaptic activity (Zito and Svoboda 2002). Therefore, the morphological changes in dendritic structure in mouse models of the disease, as well as in RTT patients, may suggest an underlying synaptic deficit in neurotransmission in the CNS. One focus of our research has been examining whether the loss of MeCP2 directly contributes to functional alterations in synaptic transmission that may ultimately contribute to the disease phenotype.

\section{MeCP2, HDACs, and synaptic transmission}

Researchers have started to uncover a number of defects in synaptic function in three different mouse models of RTT. The loss of MeCP2 function results in changes in 
spontaneous synaptic transmission as well as in short- and long-term synaptic plasticity. Two studies, one using a MeCP2-null mouse (Asaka et al. 2006) and another using a mouse expressing a truncated form of $\mathrm{MeCP} 2$ (Moretti et al. 2006), found deficits in both long-term potentiation (LTP) and long-term depression in hippocampal slices from these mice. The first study saw these changes only in older, symptomatic mice (Asaka et al. 2006), while the second found them also in younger, asymptomatic mice, suggesting the possibility that these synaptic deficits may be occurring before the manifestation of RTT-like behaviors (Moretti et al. 2006). Other defects in basal synaptic transmission were reported in these mice and in additional studies. In cortical pyramidal neurons, spontaneous and miniature excitatory postsynaptic current (mEPSC) properties were reduced in MeCP2 knockout mice while a small increase was seen in the overall synaptic charge of spontaneous inhibitor postsynaptic currents (IPSCs; Dani et al. 2005). In dissociated hippocampal cultures, we found a significant decrease in the frequency of spontaneous mEPSCs in MeCP2 knockout versus control neurons while no change was seen in mIPSC properties (Nelson et al. 2006). These changes in synaptic transmission may be quite important in underlying mechanisms of neurological dysfunction observed in RTT patients (Table 1). The results from each of these studies suggest an imbalance between excitatory and inhibitory activity in the brains of MeCP2 mutant mice, towards less excitation and therefore more inhibition. Several studies have suggested an abnormal excitation-inhibition ratio in the brains of autistic patients (Purcell et al. 2001; Rubenstein 2010; Rubenstein and Merzenich 2003; Serajee et al. 2003), therefore a similar imbalance in excitatory-inhibitory neurotransmission may be common denominator among patients with autism spectrum disorders including RTT.

Are the deficits in synaptic transmission observed in the MeCP2 null mice due to MeCP2's role as a transcriptional repressor? Previous studies have shown that $\mathrm{MeCP} 2$ is a prototypic member of the methyl-CpG-binding domain protein family linked with transcriptional repression. MeCP2 has two functional domains, a methyl-CpGbinding domain (MBD) and a transcription repressor domain (TRD). The majority of the RTT disease causing mutations occurs within these functional domains (Amir et al. 1999; Amir and Zoghbi 2000; Bienvenu et al. 2000; Huppke et al. 2000; Wan et al. 1999). MeCP2 through its MBD binding to methylated $\mathrm{CpG}$ sites and through its TRD interacts with a multiprotein corepressor complex that includes HDAC1 and HDAC2 to silence gene expression (Nan et al. 1998). HDACs are a family of enzymes that modulate chromatin plasticity, facilitating protein-DNA interactions and transcriptional control by catalyzing the removal of the acetyl group from acetylated lysines of histone proteins to repress gene expression. Several broad acting HDAC inhibitor drugs, such as Trichostatin A (TSA), are commonly used to relieve transcriptional repression (Jones et al. 1998; Nan et al. 1998).

To examine whether the synaptic deficits observed in various RTT animal models were due to MeCP2's role as a transcriptional repressor, we treated wild-type C57BL/6 hippocampal cultures with HDAC inhibitors, including TSA, and examined spontaneous neurotransmission (Nelson et al. 2006). We found inhibition of HDAC activity resulted in a similar decrease in $\mathrm{mEPSC}$ frequency to that observed in MeCP2 null neurons. This decrease was reversed when treatment of $\mathrm{C} 57 \mathrm{BL} / 6$ neurons included both TSA and an inhibitor of transcriptional activation, actinomycin $\mathrm{D}$, suggesting that newly transcribed genes are involved in the suppression of synaptic function. Importantly, this alteration in spontaneous synaptic transmission was occluded in MeCP2 $\mathrm{KO}$ neurons treated with HDAC inhibitors suggesting that $\mathrm{MeCP} 2$ may be responsible for mediating the alterations in synaptic neurotransmission through transcriptional repression. If these deficits in synaptic transmission are mediated through MeCP2's role as a transcriptional repressor, then it suggests that specific synaptic proteins may be $\mathrm{MeCP} 2$ target genes that are altered when $\mathrm{MeCP} 2$ function is impaired, as with the disease causing mutations. One intriguing aspect to this hypothesis is that the expression of synaptic genes are tightly controlled and only slight changes in their expression can profoundly influence synaptic transmission (Kim et al. 2010), which could be easily missed by a broad scale microarray approach searching for large changes in gene expression.

While our data suggests that $\mathrm{MeCP} 2$ is functioning as a transcriptional repressor in the regulation of synaptic transmission, our data was generated with broad acting HDAC inhibitors. Since HDAC1 and HDAC2 interact with DNA through interaction with $\mathrm{MeCP} 2$, we took a genetic approach to more closely examine the impact of impaired transcriptional repression on synaptic transmission. Rather surprisingly, these experiments uncovered alterations in synapse numbers as a result of modifying HDAC activity in hippocampal neurons (Akhtar et al. 2009). Treatment with HDAC inhibitors caused a significant increase in excitatory, but not inhibitory immature synaptic contacts formed between nascent hippocampal neurons. The increase in morphological excitatory synaptic markers was coupled with a robust increase in the frequency of mEPSCs suggesting an augmentation in functional excitatory synaptic contacts. Genetic deletion of both HDAC1 and HDAC2 in immature neurons produced a similar phenotype as that observed with the pharmacological inhibition of HDAC activity. Interestingly, double deletion, but not single deletion, of floxed HDAC1 and 2 using a lentiviral Cre 
Table 1 Electrophysiological phenotypes of MeCP2 mouse models

\begin{tabular}{|c|c|c|c|c|c|}
\hline Animal model & Neuronal preparation & Long-term plasticity & Basal synaptic transmission & $\begin{array}{l}\text { Favors excitation } \\
\text { or inhibition }\end{array}$ & Reference \\
\hline \multirow[t]{8}{*}{$\mathrm{MeCP} 2^{-/ y}$} & $\begin{array}{l}\text { Cortical slices from } \\
\text { symptomatic mice }^{\text {a }}\end{array}$ & N/A & $\begin{array}{l}\downarrow \text { spontaneous firing (also } \\
\text { in presymptomatic mice }{ }^{\mathrm{b}} \text { ) } \\
\downarrow \text { sEPSC charge } \\
\uparrow \text { sIPSC charge } \\
\downarrow \text { mEPSC amplitudes }\end{array}$ & Inhibition & $\begin{array}{l}\text { Dani et al. } \\
\text { (2005) }\end{array}$ \\
\hline & $\begin{array}{l}\text { Cortical slices from } \\
\text { presymptomatic mice }\end{array}$ & Normal LTP & $\begin{array}{l}\downarrow \text { EPSP amplitudes } \\
\downarrow \text { EPSP amplitude } \mathrm{CV}^{-2} \\
\downarrow \text { Connection probability }\end{array}$ & Inhibition & $\begin{array}{l}\text { Dani and Nelson } \\
\text { (2009) }\end{array}$ \\
\hline & $\begin{array}{l}\text { Cortical slices from } \\
\text { symptomatic mice }\end{array}$ & N/A & $\begin{array}{l}\downarrow \text { EPSC frequency and } \\
\text { amplitudes }\end{array}$ & Inhibition & $\begin{array}{l}\text { Tropea et al. } \\
\text { (2009) }\end{array}$ \\
\hline & $\begin{array}{l}\text { Hippocampal slices } \\
\text { from symptomatic } \\
\text { mice }\end{array}$ & $\downarrow$ LTP and LTD & $\downarrow$ fEPSP PPR & $?$ & $\begin{array}{l}\text { Asaka et al. } \\
\text { (2006) }\end{array}$ \\
\hline & \multirow[t]{2}{*}{$\begin{array}{l}\text { Dissociated hippocampal } \\
\text { cultures }\end{array}$} & \multirow[t]{2}{*}{ N/A } & $\begin{array}{l}\downarrow \text { mEPSC frequency } \\
\downarrow \text { EPSC PPR }\end{array}$ & \multirow[t]{2}{*}{ Inhibition } & \multirow[t]{2}{*}{$\begin{array}{l}\text { Nelson et al. } \\
\text { (2006) }\end{array}$} \\
\hline & & & $\begin{array}{l}\uparrow 10 \mathrm{~Hz} \text { EPSC amplitude } \\
\text { depression }\end{array}$ & & \\
\hline & \multirow[t]{2}{*}{$\begin{array}{l}\text { Autaptic hippocampal } \\
\text { cultures }\end{array}$} & \multirow[t]{2}{*}{ N/A } & $\begin{array}{l}\downarrow \text { eEPSC amplitudes } \\
\downarrow \mathrm{mESPC} \text { frequency }\end{array}$ & \multirow[t]{2}{*}{ Inhibition } & \multirow[t]{2}{*}{$\begin{array}{l}\text { Chao et al. } \\
(2007)\end{array}$} \\
\hline & & & $\begin{array}{l}\downarrow \text { EPSC charge in response } \\
\text { to hypertonic sucrose }\end{array}$ & & \\
\hline $\mathrm{MeCP} 2^{308 / y}$ & $\begin{array}{l}\text { Hippocampal and cortical } \\
\text { slices from symptomatic } \\
\text { mice }\end{array}$ & $\begin{array}{l}\text { Hippocampus: } \downarrow \text { LTP and LTD } \\
\text { Cortex: } \downarrow \text { LTP }\end{array}$ & $\begin{array}{l}\text { Hippocampus: fEPSP- } \\
\text { fiber volley slope ratio } \\
\downarrow \text { fEPSP PPR }\end{array}$ & $?$ & $\begin{array}{l}\text { Moretti et al. } \\
(2006)\end{array}$ \\
\hline \multirow[t]{3}{*}{$\mathrm{MeCP} 2^{\operatorname{Tg} 1}$} & Hippocampal slices & $\uparrow \mathrm{LTP}$ & $\uparrow f E P S P$ PPR & $?$ & $\begin{array}{l}\text { Collins et al. } \\
\text { (2004) }\end{array}$ \\
\hline & \multirow[t]{2}{*}{$\begin{array}{l}\text { Autaptic hippocampal } \\
\text { cultures }\end{array}$} & \multirow[t]{2}{*}{ N/A } & $\begin{array}{l}\uparrow \mathrm{eEPSC} \text { amplitudes } \\
\uparrow \mathrm{mEPSC} \text { frequency }\end{array}$ & \multirow[t]{2}{*}{ Excitation } & \multirow[t]{2}{*}{$\begin{array}{l}\text { Chao et al. } \\
\text { (2007) }\end{array}$} \\
\hline & & & $\begin{array}{l}\uparrow E P S C \text { charge in response } \\
\text { to hypertonic sucrose }\end{array}$ & & \\
\hline
\end{tabular}

sEPSC spontaneous excitatory postsynaptic current, $s I P S C$ spontaneous inhibitory postsynaptic current, $m E S P C$ miniature excitatory postsynaptic currents, $L T P$ long-term potentiation, EPSP excitatory postsynaptic potential, $C V^{-2}$ inverse square of the coefficient of variation, $L T D$ long-term depression, $f E P S P$ field EPSP, $P P R$ paired pulse ratio, eEPSC evoked EPSC

${ }^{\mathrm{a}}>4$ weeks of age

${ }^{b} \leq 4$ weeks of age

recombinase system was required to trigger a significant increase in mEPSC frequency, suggesting that both HDAC1 and HDAC2 are important for controlling synapse number in immature neurons.

In contrast, in mature hippocampal neurons, treatment with the HDAC inhibitor TSA or deletion of HDAC2 alone resulted in a decrease in the frequency of mEPSCs with no changes in excitatory synapse number (Akhtar et al. 2009; Nelson et al. 2006). Accordingly, HDAC2 overexpression caused an increase in mEPSC frequency (Akhtar et al. 2009). Altogether, these data suggest that histone acetylation can regulate the formation of synapses in hippocampal neurons, with HDAC1 and HDAC2 playing both redundant and distinct roles during the time course of neuronal maturation. Some aspects of basal synaptic transmission, such as subtle changes in presynaptic neurotransmitter release, may also be controlled by histone acetylation.

Long-term synaptic plasticity and learning and memoryrelated behaviors also appear to be regulated by HDAC activity. TSA and other broad scale HDAC inhibitors have been utilized in the brains of mice and were found to enhance induction of hippocampal LTP and promote hippocampus-dependent associative memory (Bredy and Barad 2008; Bredy et al. 2007; Lattal et al. 2007; Vecsey et al. 2007). A recent study helped delineate which specific HDAC enzymes are important for bringing about many of the memory and long-term synaptic plasticity enhancements seen with non-specific HDAC inhibitors. It was discovered that mice with HDAC2 overexpression, but not $\mathrm{HDAC} 1$, have impaired learning and memory and display 
deficits in hippocampal LTP, while mice lacking neuronal expression of HDAC2 display enhanced hippocampaldependent memory formation and LTP, suggesting that HDAC2 is a negative regulator of memory formation (Guan et al. 2009). All together, these findings highlight the importance of histone acetylation and deacetylation in controlling various aspects of synaptic transmission along with an animal's ability to form long-term memories.

\section{DNA methylation and synaptic function}

The function of MeCP2 is, at least partially, dependent on its ability to bind methylated DNA, implicating the importance of this epigenetic mechanism in synapse function. DNA methylation negatively regulates gene expression via the addition of methyl groups at the 5position of cytosine residues within $\mathrm{CpG}$ dinucleotides of the promoter regions of genes. In mammals, the enzymes responsible for establishing and maintaining DNA methylation patterns are the DNA methyltransferases (DNMTs) 1, $3 \mathrm{a}$, and 3b. DNMT3a and DNMT3b are de novo methyltransferases that establish methylation patterns at specific sites within the genome, while DNMT1 is responsible for the maintenance of these patterns after DNA replication (Jaenisch and Bird 2003). DNA methyltransferases, in particular DNMT1 and 3a, are highly expressed in neurons in the adult brain, suggesting they may have an important functional role in postmitotic neurons (Brooks et al. 1996; Feng et al. 2005; Goto et al. 1994; Inano et al. 2000). Furthermore, specific neurodevelopment disorders, Rett syndrome and fragile $\mathrm{X}$ syndrome, arise from misinterpretation and dysregulation of DNA methylation, respectively (Amir et al. 1999; Turner et al. 1996). These observations have identified a need for understanding the role of DNA methylation in the mature brain, an area of study that, until recently, has been largely not studied due to the longstanding opinion that DNA methylation patterns are generally static in non-dividing cells (Ehrlich 2003).

The DNA methyltransferases, DNMT1 and 3a, are highly expressed in adult postmitotic hippocampal neurons (Feng et al. 2005; Goto et al. 1994), indicating a possible role for DNA methylation in the control of both synaptic transmission and learning and memory. We have recently demonstrated that DNMT inhibition in wild-type hippocampal neurons resulted in activity-dependent demethylation of genomic DNA and a parallel decrease in the frequency of miniature excitatory postsynaptic currents, which in turn impacted neuronal excitability and network activity (Nelson et al. 2008). Treatment with DNMT inhibitors revealed an activity-driven demethylation of the brain-derived neurotrophic factor $(B d n f)$ promoter I, which was mediated by synaptic activation of NMDA receptors, as it was susceptible to AP5, a blocker of NMDA receptors. Interestingly, enhancing excitatory activity, in the absence of DNMT inhibitors, also produced similar decreases in DNA methylation and mEPSC frequency, suggesting a role for DNA methylation in the control of homeostatic synaptic plasticity. Furthermore, adding excess substrate for DNA methylation ( $S$-adenosyl-L-methionine) rescued the suppression of mEPSCs by DNMT inhibitors in wild-type neurons (Nelson et al. 2008). Additional studies have shown impairments in long-term memory and synaptic plasticity associated with a decrease in the methylation of neuronal plasticity genes following inhibition of DNA methylation (Levenson et al. 2006; Miller and Sweatt 2007). These results demonstrate the importance of maintaining DNMT activity within mature neurons for proper synapse functioning. A recent study expanded on these findings using DNMT1 and 3a conditional KO mice and found that both enzymes appear to play redundant roles in the regulation of long-term synaptic plasticity (Feng et al. 2010). One intriguing hypothesis is that the loss of DNMT1 or $3 \mathrm{a}$ in hippocampal neurons results in deficits of synaptic function that lead to an imbalance in excitatory and inhibitory synaptic transmission, reminiscent of previous observations in dissociated cultures treated with DNMT inhibitors (Nelson et al. 2008). DNA methylation induced changes in basal synaptic transmission could ultimately lead to additional deficits in synaptic activity and behavior.

\section{Conclusion}

The neurological and neurodevelopmental deficits seen in patients with Rett syndrome are believed to be a result of abnormal neuronal gene expression brought about by the loss of MeCP2 function. Recent studies, including work from our group, have shown that this altered gene expression, in turn, triggers various synaptic abnormalities ranging from deficits in synaptogenesis to control of neurotransmitter release and long-term synaptic plasticity. Some of these synaptic modifications can also be mimicked by manipulation of HDAC enzymes that comprise key members of the MeCP2 corepressor complex. Furthermore, inhibition of DNA methyltransferases or other manipulation of DNMT function can also elicit similar changes in synaptic function underlying the essential role of $\mathrm{MeCP} 2$, HDACs, and proper DNA methylation regulation in maintenance and plasticity of central synapses. Although synaptic molecular targets of these transcriptional mechanisms remain unclear, these findings provide strong motivation to evaluate therapeutic interventions that may target the synaptic phenotypes such as augmenting excitatory neurotransmission or suppressing inhibitory neuro- 
transmission to achieve a rebalance of synaptic activity. Once specific molecular targets are elucidated, ultimately one can design synapse specific approaches as an effective complement to the currently expanding repertoire of drugs targeting nuclear signaling and gene regulation for the treatment of CNS disorders.

Acknowledgments This work was supported by National Institute of Health grants MH081060 (L.M.M.) and MH066198 (E.T.K.).

\section{References}

Akhtar MW, Raingo J, Nelson ED, Montgomery RL, Olson EN, Kavalali ET, et al. Histone deacetylases 1 and 2 form a developmental switch that controls excitatory synapse maturation and function. J Neurosci. 2009;29:8288-97.

Amir RE, Zoghbi HY. Rett syndrome: methyl-CpG-binding protein 2 mutations and phenotype-genotype correlations. Am J Med Genet. 2000;97:147-52.

Amir RE, Van den Veyver IB, Wan M, Tran CQ, Francke U, Zoghbi HY. Rett syndrome is caused by mutations in X-linked MECP2, encoding methyl-CpG-binding protein 2. Nat Genet. 1999;23:185-8.

Asaka Y, Jugloff DG, Zhang L, Eubanks JH, Fitzsimonds RM. Hippocampal synaptic plasticity is impaired in the Mecp2-null mouse model of Rett syndrome. Neurobiol Dis. 2006;21:217-27.

Ballas N, Lioy DT, Grunseich C, Mandel G. Non-cell autonomous influence of MeCP2-deficient glia on neuronal dendritic morphology. Nat Neurosci. 2009;12:311-7.

Ballestar E, Yusufzai TM, Wolffe AP. Effects of Rett syndrome mutations of the methyl-CpG binding domain of the transcriptional repressor $\mathrm{MeCP} 2$ on selectivity for association with methylated DNA. Biochemistry. 2000;39:7100-6.

Bienvenu T, Carrie A, de Roux N, Vinet MC, Jonveaux P, Couvert P, et al. MECP2 mutations account for most cases of typical forms of Rett syndrome. Hum Mol Genet. 2000;9:1377-84.

Bredy TW, Barad M. The histone deacetylase inhibitor valproic acid enhances acquisition, extinction, and reconsolidation of conditioned fear. Learn Mem. 2008;15:39-45.

Bredy TW, Wu H, Crego C, Zellhoefer J, Sun YE, Barad M. Histone modifications around individual BDNF gene promoters in prefrontal cortex are associated with extinction of conditioned fear. Learn Mem. 2007;14:268-76.

Brooks PJ, Marietta C, Goldman D. DNA mismatch repair and DNA methylation in adult brain neurons. J Neurosci. 1996;16:939-45.

Chahrour M, Jung SY, Shaw C, Zhou X, Wong ST, Qin J, et al. $\mathrm{MeCP} 2$, a key contributor to neurological disease, activates and represses transcription. Science. 2008;320:1224-9.

Chao HT, Zoghbi HY, Rosenmund C. MeCP2 controls excitatory synaptic strength by regulating glutamatergic synapse number. Neuron. 2007;56:58-65

Chao HT, Chen H, Samaco RC, Xue M, Chahrour M, Yoo J, et al. Dysfunction in GABA signalling mediates autism-like stereotypies and Rett syndrome phenotypes. Nature. 2010;468:263-9.

Chen RZ, Akbarian S, Tudor M, Jaenisch R. Deficiency of methylCpG binding protein-2 in CNS neurons results in a Rett-like phenotype in mice. Nat Genet. 2001;27:327-31.

Collins AL, Levenson JM, Vilaythong AP, Richman R, Armstrong DL, Noebels JL, et al. Mild overexpression of MeCP2 causes a progressive neurological disorder in mice. Hum Mol Genet. 2004;13:2679-89.
Dani VS, Nelson SB. Intact long-term potentiation but reduced connectivity between neocortical layer 5 pyramidal neurons in a mouse model of Rett syndrome. J Neurosci. 2009;29:11263-70.

Dani VS, Chang Q, Maffei A, Turrigiano GG, Jaenisch R, Nelson SB. Reduced cortical activity due to a shift in the balance between excitation and inhibition in a mouse model of Rett syndrome. Proc Natl Acad Sci USA. 2005;102:12560-5.

Deisseroth K, Mermelstein PG, Xia H, Tsien RW. Signaling from synapse to nucleus: the logic behind the mechanisms. Curr Opin Neurobiol. 2003;13:354-65.

Ehrlich M. Expression of various genes is controlled by DNA methylation during mammalian development. J Cell Biochem. 2003;88:899-910.

Feng J, Chang H, Li E, Fan G. Dynamic expression of de novo DNA methyltransferases Dnmt3a and Dnmt3b in the central nervous system. J Neurosci Res. 2005;79:734-46.

Feng J, Zhou Y, Campbell SL, Le T, Li E, Sweatt JD, et al. Dnmt1 and Dnmt3a maintain DNA methylation and regulate synaptic function in adult forebrain neurons. Nat Neurosci. 2010;13:423-30.

Francke U. Mechanisms of disease: neurogenetics of MeCP2 deficiency. Nat Clin Pract Neurol. 2006;2:212-21.

Fyffe SL, Neul JL, Samaco RC, Chao HT, Ben-Shachar S, Moretti P, et al. Deletion of Mecp2 in Sim1-expressing neurons reveals a critical role for $\mathrm{MeCP} 2$ in feeding behavior, aggression, and the response to stress. Neuron. 2008;59:947-58.

Gemelli T, Berton O, Nelson ED, Perrotti LI, Jaenisch R, Monteggia LM. Postnatal loss of methyl-CpG binding protein 2 in the forebrain is sufficient to mediate behavioral aspects of Rett syndrome in mice. Biol Psychiatry. 2006;59:468-76.

Goto K, Numata M, Komura JI, Ono T, Bestor TH, Kondo H. Expression of DNA methyltransferase gene in mature and immature neurons as well as proliferating cells in mice. Differentiation. 1994;56:39-44.

Guan JS, Haggarty SJ, Giacometti E, Dannenberg JH, Joseph N, Gao $\mathrm{J}$, et al. HDAC2 negatively regulates memory formation and synaptic plasticity. Nature. 2009;459:55-60.

Guy J, Hendrich B, Holmes M, Martin JE, Bird A. A mouse Mecp2null mutation causes neurological symptoms that mimic Rett syndrome. Nat Genet. 2001;27:322-6.

Hagberg B, Aicardi J, Dias K, Ramos O. A progressive syndrome of autism, dementia, ataxia, and loss of purposeful hand use in girls: Rett's syndrome: report of 35 cases. Ann Neurol. 1983;14:471-9.

Huppke P, Laccone F, Kramer N, Engel W, Hanefeld F. Rett syndrome: analysis of MECP2 and clinical characterization of 31 patients. Hum Mol Genet. 2000;9:1369-75.

Inano K, Suetake I, Ueda T, Miyake Y, Nakamura M, Okada M, et al. Maintenance-type DNA methyltransferase is highly expressed in post-mitotic neurons and localized in the cytoplasmic compartment. J Biochem. 2000;128:315-21.

Jaenisch R, Bird A. Epigenetic regulation of gene expression: how the genome integrates intrinsic and environmental signals. Nat Genet. 2003;33(Suppl):245-54.

Jones PL, Veenstra GJ, Wade PA, Vermaak D, Kass SU, Landsberger $\mathrm{N}$, et al. Methylated DNA and MeCP2 recruit histone deacetylase to repress transcription. Nat Genet. 1998;19:187-91.

Jugloff DG, Jung BP, Purushotham D, Logan R, Eubanks JH. Increased dendritic complexity and axonal length in cultured mouse cortical neurons overexpressing methyl-CpG-binding protein MeCP2. Neurobiol Dis. 2005;19:18-27.

Kaufmann WE, Moser HW. Dendritic anomalies in disorders associated with mental retardation. Cereb Cortex. 2000;10:98191.

Kim TK, Hemberg M, Gray JM, Costa AM, Bear DM, Wu J, et al. Widespread transcription at neuronal activity-regulated enhancers. Nature. 2010;465:182-7. 
Kishi N, Macklis JD. MECP2 is progressively expressed in postmigratory neurons and is involved in neuronal maturation rather than cell fate decisions. Mol Cell Neurosci. 2004;27:306-21.

Lasalle JM, Yasui DH. Evolving role of MeCP2 in Rett syndrome and autism. Epigenomics. 2009;1:119-30.

Lattal KM, Barrett RM, Wood MA. Systemic or intrahippocampal delivery of histone deacetylase inhibitors facilitates fear extinction. Behav Neurosci. 2007;121:1125-31.

Levenson JM, Roth TL, Lubin FD, Miller CA, Huang IC, Desai P, et al. Evidence that DNA (cytosine-5) methyltransferase regulates synaptic plasticity in the hippocampus. J Biol Chem. 2006;281:15763-73.

Matarazzo V, Cohen D, Palmer AM, Simpson PJ, Khokhar B, Pan SJ, et al. The transcriptional repressor Mecp2 regulates terminal neuronal differentiation. Mol Cell Neurosci. 2004;27:44-58.

Miller CA, Sweatt JD. Covalent modification of DNA regulates memory formation. Neuron. 2007;53:857-69.

Moretti P, Levenson JM, Battaglia F, Atkinson R, Teague R, Antalffy $\mathrm{B}$, et al. Learning and memory and synaptic plasticity are impaired in a mouse model of Rett syndrome. J Neurosci. 2006;26:319-27.

Nan X, Ng HH, Johnson CA, Laherty CD, Turner BM, Eisenman RN, et al. Transcriptional repression by the methyl-CpG-binding protein $\mathrm{MeCP} 2$ involves a histone deacetylase complex. Nature. 1998;393:386-9.

Nelson ED, Kavalali ET, Monteggia LM. MeCP2-dependent transcriptional repression regulates excitatory neurotransmission. Curr Biol. 2006;16:710-6.

Nelson ED, Kavalali ET, Monteggia LM. Activity-dependent suppression of miniature neurotransmission through the regulation of DNA methylation. J Neurosci. 2008;28:395-406.

Purcell AE, Jeon OH, Zimmerman AW, Blue ME, Pevsner J. Postmortem brain abnormalities of the glutamate neurotransmitter system in autism. Neurology. 2001;57:1618-28.

Ravn K, Nielsen JB, Schwartz M. Mutations found within exon 1 of MECP2 in Danish patients with Rett syndrome. Clin Genet. 2005;67:532-3.

Rubenstein JL. Three hypotheses for developmental defects that may underlie some forms of autism spectrum disorder. Curr Opin Neurol. 2010;23:118-23.
Rubenstein JL, Merzenich MM. Model of autism: increased ratio of excitation/inhibition in key neural systems. Genes Brain Behav. 2003;2:255-67.

Samaco RC, Mandel-Brehm C, Chao HT, Ward CS, Fyffe-Maricich $\mathrm{SL}$, Ren $\mathrm{J}$, et al. Loss of MeCP2 in aminergic neurons causes cell-autonomous defects in neurotransmitter synthesis and specific behavioral abnormalities. Proc Natl Acad Sci USA. 2009;106:21966-71.

Serajee FJ, Zhong H, Nabi R, Huq AH. The metabotropic glutamate receptor 8 gene at $7 \mathrm{q} 31$ : partial duplication and possible association with autism. J Med Genet. 2003;40:e42.

Shahbazian M, Young J, Yuva-Paylor L, Spencer C, Antalffy B, Noebels $\mathrm{J}$, et al. Mice with truncated $\mathrm{MeCP} 2$ recapitulate many Rett syndrome features and display hyperacetylation of histone H3. Neuron. 2002;35:243-54.

Tate P, Skarnes W, Bird A. The methyl-CpG binding protein MeCP2 is essential for embryonic development in the mouse. Nat Genet. 1996; 12:205-8.

Tropea D, Giacometti E, Wilson NR, Beard C, McCurry C, Fu DD, et al. Partial reversal of Rett syndrome-like symptoms in MeCP2 mutant mice. Proc Natl Acad Sci USA. 2009;106:2029-34.

Tudor M, Akbarian S, Chen RZ, Jaenisch R. Transcriptional profiling of a mouse model for Rett syndrome reveals subtle transcriptional changes in the brain. Proc Natl Acad Sci USA. 2002;99:15536-41.

Turner G, Webb T, Wake S, Robinson H. Prevalence of fragile X syndrome. Am J Med Genet. 1996;64:196-7.

Vecsey CG, Hawk JD, Lattal KM, Stein JM, Fabian SA, Attner MA, et al. Histone deacetylase inhibitors enhance memory and synaptic plasticity via CREB:CBP-dependent transcriptional activation. J Neurosci. 2007;27:6128-40.

Wan M, Lee SS, Zhang X, Houwink-Manville I, Song HR, Amir RE, et al. Rett syndrome and beyond: recurrent spontaneous and familial MECP2 mutations at CpG hotspots. Am J Hum Genet. $1999 ; 65: 1520-9$.

Yusufzai TM, Wolffe AP. Functional consequences of Rett syndrome mutations on human MeCP2. Nucleic Acids Res. 2000;28:41729.

Zito K, Svoboda K. Activity-dependent synaptogenesis in the adult Mammalian cortex. Neuron. 2002;35:1015-7. 